\title{
Role of A Disintegrin And Metalloprotease-12 in Neutrophil Recruitment Induced by Airway Epithelium
}

\author{
Cecilia Estrella ${ }^{1 *}$, Natacha Rocks ${ }^{2 *}$, Geneviève Paulissen², Florence Quesada-Calvo ${ }^{2}$, Agnès Noël$^{2}$, Eva Vilain ${ }^{1}$, \\ Philippe Lassalle1, Isabelle Tillie-Leblond ${ }^{1,3}$, Didier Cataldo ${ }^{2, \ddagger}$, and Philippe Gosset ${ }^{1, \ddagger}$ \\ ${ }^{1}$ INSERM U774, Biomolecules and Pulmonary Inflammation; Institut Pasteur; and Université de Lille II, Lille, France; ${ }^{2}$ Department of Biology of \\ Tumours and Development, GIGA-Research $\left(\mathrm{GIGA-} \mathrm{I}^{3}\right)$, University of Liège and $\mathrm{CHU}$ of Liège, Liège, Belgium; and ${ }^{3} \mathrm{Clinique}$ des Maladies \\ Respiratoires Hôpital Calmette, CHRU, Lille, France
}

\begin{abstract}
Among proteases, metalloproteases are implicated in tissue remodeling, as shown in numerous diseases including allergy. ADAMs (A Disintegrin And Metalloprotease) metalloproteases are implicated in physiologic processes such as cytokine and growth factor shedding, cell migration, adhesion, or repulsion. Our aim was to measure ADAM-12 expression in airway epithelium and to define its role during the allergic response. To raise this question, we analyzed the ADAM-12 expression ex vivo after allergen exposure in patients with allergic rhinitis and in vitro in cultured primary human airway epithelial cells (AEC). Clones of BEAS-2B cells transfected with the full-length form of ADAM-12 were generated to study the consequences of ADAM-12 up-regulation on AEC function. After allergen challenge, a strong increase of ADAM-12 expression was observed in airway epithelium from patients with allergic rhinitis but not from control subjects. In contrast with the other HB-epidermal growth factor sheddases, ADAM-10 and -17, TNF- $\alpha$ in vitro increased the expression of ADAM-12 by AEC, an effect amplified by IL-4 and IL-13. Up-regulation of ADAM-12 in AEC increased the expression of $\alpha 3$ and $\alpha 4$ integrins and to the modulation of cell migration on fibronectin but not on collagen. Moreover, overexpression of ADAM-12 in BEAS-2B enhanced the secretion of CXCL1 and CXCL8 and their capacity to recruit neutrophils. CD47 was strongly decreased by ADAM-12 overexpression, a process associated with a reduced adhesion of neutrophils. These effects were mainly dependent on epidermal growth factor receptor activation. In summary, ADAM-12 is produced during allergic reaction by $A E C$ and might increase neutrophil recruitment within airway mucosa.
\end{abstract}

Keywords: ADAM-12; allergy; airway epithelial cell; neutrophil; inflammation

(Received in original form March 31, 2008 and in final form November 3, 2008)

* These authors contributed equally to this work.

¥ These authors contributed equally to this work.

This work was supported by grants from the Conseil Régional du Nord-Pas de Calais-FEDER (Projet THERADAM), the Communauté française de Belgique (Actions de Recherches Concertées), the Fonds de la Recherche Scientifique Médicale, the Fonds National de la Recherche Scientifique (F.N.R.S., Belgium), the Fonds spéciaux de la Recherche (University of Liège), the Fortis Banque Assurances, the Fondation Léon Fredericq (University of Liège), the D.G.T.R.E. from the $\ll$ Région Wallonne $\gg$, the F.S.E. (Fonds Social Européen), the Fonds $\mathrm{d}^{\prime}$ Investissements de la Recherche Scientifique (F.I.R.S., CHU, Liège, Belgium) and the Interuniversity Attraction Poles Programme-Belgian Science Policy (Brussels, Belgium). N.R. is a fellow of the Télévie Program (FNRS, Belgium), G.P. is a research fellow from the FRIA program (FNRS, Belgium), and D.C. is a research associate from the FNRS.

Correspondence and requests for reprints should be addressed to Philippe Gosset, Ph.D., INSERM U774, Biomolecules and Pulmonary Inflammation, Institut Pasteur de Lille, 1 rue du Pr Calmette, BP245, 59019 Lille Cedex, France. E-mail: Philippe.Gosset@pasteur-lille.fr

This article has an online supplement, which is accessible from this issue's table of contents at www.atsjournals.org

Am J Respir Cell Mol Biol Vol 41. pp 449-458, 2009

Originally Published in Press as DOI: 10.1165/rcmb.2008-01240C on February 12, 2009

Internet address: www.atsjournals.org

\section{CLINICAL RELEVANCE}

A Disintegrin And Metalloprotease (ADAM)-12 is a metalloprotease that possesses an important sheddase activity. ADAM-12 up-regulation during allergic airway diseases and its implication in the control of neutrophil recruitment by airway epithelial cells suggest its involvement in the control of airway inflammation.

Allergic diseases, including asthma and allergic rhinitis, are chronic respiratory diseases characterized by a predominant $\mathrm{T}$ helper cell type 2 (Th2) inflammation, airway hyperresponsiveness, and airflow obstruction. At the beginning of the disease, these symptoms are reversible, but may become irreversible when the disease progresses as airways remodeling develops. Histologic studies have described that patients with asthma display airway wall abnormalities mainly consisting in an increase in smooth muscle mass, mucus gland hypertrophy, extracellular matrix changes (i.e., collagen deposition), and inflammatory cell infiltration mainly composed of eosinophils, $\mathrm{T}$ lymphocytes, and mast cells (1). In severe asthma, an influx of neutrophils in the airways has also been observed (2). The exaggerated decrease in forced expiratory volume at the first second $\left(\mathrm{FEV}_{1}\right)$ in patients with chronic asthma is generally considered to be at least in part due to these airway structural changes. Although less obvious, structural changes are also present in allergic rhinitis and frequently associated with the recruitment of neutrophils (3).

Matrix metalloproteases (MMPs) are implicated in tissue remodeling, as shown in numerous diseases, including allergy. Indeed, MMP-2, -3, -9, -12 have been implicated in different steps of the disease (4-7). Other members of the vast zinc proteases family, the ADAM (A Disintegrin And Metalloprotease), which are either membrane-anchored or secreted metalloproteases, and the ADAMTS (ADAM with ThromboSpondin motifs), have emerged as asthma associated genes. Indeed, ADAM-33 polymorphism was identified as a gene associated with bronchial hyperresponsiveness in humans (8), and ADAM-8 up-regulation was reported in a murine model of allergic asthma by microarray analysis (9). More recently, Paulissen and coworkers (10) observed an increased expression of ADAM- $8,-9$, and - 12 mRNA in induced sputum from patients with asthma as compared with control subjects while, on the contrary, ADAMTS- 1 and -15 mRNA levels were decreased.

Proteases belonging to the ADAM family share a highly conserved domain structure: an N-terminal secretion signal, a prodomain, a metalloprotease domain, a disintegrin domain, a cystein-rich region followed by an epidermal growth factor (EGF) repeat, and a transmembrane domain ended by a cytoplasmic tail. ADAMs are implicated in physiologic processes such as cytokine and growth factor shedding, cell migration, cell adhesion, or repulsion $(11,12)$. These properties explain their 
involvement in complex events such as myogenesis or fertilization, and suggest a role in inflammatory and immune reactions.

ADAM-12 encodes two different forms: a membrane-bound (long) form, ADAM-12L, and an alternatively spliced secreted form, ADAM-12S (13). Previous reports showed that ADAM-12 supports cell attachment through its interaction with integrins $(\alpha 3, \alpha 4$, and $\alpha 5)$ and with syndecan-4 (14-16). Moreover, ADAM-12 is also implicated in the transactivation of epidermal growth factor receptor (EGFR) through the shedding of ligands such as HB-EGF $(17,18)$, although ADAM-10 and ADAM-17 also play important roles in this process (19). ADAM-12 is expressed in high amounts in tissues characterized by rapid growth, including tumors and human placenta (13, 20-22).

In preliminary experiments using a microarray-based approach, we identified that ADAM-12 is up-regulated in bronchial epithelial cells activated by a proinflammatory mediator such as TNF- $\alpha$. Since allergic reaction is associated with the production of proinflammatory cytokines $(23,24)$, we hypothesized that the expression of ADAM-12 might be increased in airway epithelium during the allergic response and might participate in the modulation of inflammatory reaction and tissue remodeling. To raise this question, we first analyzed the expression of this metalloprotease ex vivo in patients with allergic rhinitis exposed to allergens and in vitro in human airway epithelial cells. We also defined the consequences of ADAM-12 up-regulation on airway epithelial cell (AEC) behavior by generating clones of BEAS-2B cells transfected with ADAM-12L. Our data show that ADAM-12 expression is increased after allergen exposure in allergic patients and by TNF- $\alpha$ stimulation in AEC. Moreover, ADAM-12 overexpression in AEC is associated with modifications of cell adhesion, integrin expression, and cytokine production through the activation of EGFR. This process might be responsible for modifications of the interactions between AEC and neutrophils associated with allergic diseases.

\section{MATERIALS AND METHODS}

\section{Immunohistochemistry on Nasal Biopsies Sections}

Nasal biopsies were obtained from three patients with allergic rhinitis with a history of house dust mite perennial rhinitis and a positive prick test to the antigen extract, and from three healthy subjects. Nasal biopsies were performed in turbinates at baseline (at distance from any symptoms) and 24 hours after an allergen provocation with 100 IR Dpt allergen as described elsewhere (2). Every patient with allergic rhinitis presented after allergen challenge an early and a late reaction as defined by the clinical score (25) associated with an inflammatory infiltrate within the nasal mucosa, whereas no obvious reaction or influx was detected in control subjects. These procedures were reviewed and approved by the Hospital Institutional Review Board, and a written informed consent was obtained from all subjects included in the study.

Immunohistochemistry analysis for ADAM-12 was performed on paraffin-embedded sections. First, sections were deparaffinized and treated for $\mathrm{Ag}$ retrieval by incubation at $90^{\circ} \mathrm{C}$ for 20 minutes in citrate buffer $(10 \mathrm{mM}, \mathrm{pH} 6)$. Sections were then incubated with goat IgG antiADAM-12 (N-terminal domain) antibody (Abcam, Paisley, UK) at the concentration of $2 \mu \mathrm{g} / \mathrm{ml}$ in PBS with $2 \% \mathrm{AB}^{+}$normal human serum. After washings, the binding was detected by incubation with biotinylated anti-goat IgG and then with the ABC-alkaline phosphatase kit (Vector, Burlingame, CA). Enzymatic activity was revealed in red with Fast Red and sections were counterstained with hematoxylin (Sigma-Aldrich, St. Louis, MO). The number of epithelial cells positive for ADAM-12 was quantified in the epithelial layers from all the samples. Measurements were performed by two independent observers and the coefficient of variation among them was below $10 \%$.

\section{Cell Culture, Stable Transfection, and Treatments}

Primary cultures of human Airway Epithelial Cells (AEC) were generated by culturing human bronchial epithelial explants as described previously (26). Briefly, human bronchial epithelial biopsies were obtained by fiberoptic bronchoscopy from patients who were being investigated for chronic cough or cancer. Biopsies were taken largely at distance from all lesions. Histologic features of the bronchial mucosa were normal in all specimens. Explants $(\sim 0.5 \times 0.5 \mathrm{~mm}$ in size $)$ were placed onto a well of a 6-well plate culture plastic dishes coated with collagen $G$ matrix (type I and III collagen; Biochrom KG, Berlin, Germany). After an adherence phase, explants were cultured in DMEM/F12 medium (Gibco, Paisley, UK) containing 1\% Ticarpen (GlaxoSmithKline, Marly-le-Roi, France), $2 \mathrm{mM}$ L-Glutamine, $2 \%$ Ultroser $\mathrm{G}$, and $2.5 \mu \mathrm{g} / \mathrm{ml}$ Fungizone (Invitrogen, Paisley, UK) until AEC were confluent. Then, explants were removed and confluent epithelial cells were incubated with $20 \mathrm{ng} / \mathrm{ml} \mathrm{TNF}-\alpha$ or in culture medium alone as control.

All procedures were reviewed and approved by Hospital Institutional Review Board, and a written informed consent was obtained from all subjects included in the study.

Human BEAS-2B cells were obtained from American Type Culture Collection (Manassas, VA). As described elsewhere (18), BEAS-2B cells which spontaneously express very low amounts of ADAM-12L were stably transfected with pcDNA3-neo plasmid encoding human ADAM-12L cDNA, kindly provided by Dr. Ulla Wewer (Copenhagen, Denmark). Cells were grown in Airway Epithelial Cell Basal Medium supplemented with Supplement Pack (Promocell, Heidelberg, Germany) in presence of $0.1 \mathrm{mg} / \mathrm{ml} \mathrm{G} 418$ (Invitrogen) for stable transfectants. AEC, BEAS-2B cells and ADAM-12 transfected clones were starved in Airway Epithelial Cell Basal Medium with $0.1 \%$ BSA deprived of Supplement Pack overnight before each experiment and then stimulated or not with 5, 20 or $50 \mathrm{ng} / \mathrm{ml} \mathrm{TNF} \alpha$ (Peprotech, Rocky Hill, NJ), IL-4 (Promocell), IL-13 (Peprotech) or culture medium alone as control for $1,2,6,8,12$, or 24 hours depending on the experiment. In some experiments, the effect of rh-EGF (10 ng/ml; Promocell) and of the inhibitor of EGFR activator AG1478 (15 nM; Calbiochem, VWR International, Darmstadt, Germany) was also evaluated.

\section{Neutrophil Isolation}

Neutrophils were isolated from the peripheral venous blood of healthy human volunteers. First, peripheral blood mononuclear cell (PBMC) layers prepared by density centrifugation on Ficoll-Paque (Amersham Biosciences, Uppsala, Sweden) were discarded. Then the polymorphonuclear neutrophil (PMN) layer was removed and remaining erythrocytes were eliminated with lysis buffer by hemolysis (LBH, $155 \mathrm{mM}$ $\mathrm{NH}_{4} \mathrm{Cl}, 10 \mathrm{mM} \mathrm{KHCO}, 0.1 \mathrm{mM}$ EDTA). After centrifugation and rinsing, the neutrophils isolated were resuspended in RPMI 1640 (Invitrogen) and kept on ice until the experiment.

\section{Quantitative Real-Time PCR}

Total RNA was isolated from AEC, BEAS-2B, or ADAM-12 transfected clones. After treatment, cells were washed in sterile cold PBS, snap-frozen, and stored at $-80^{\circ}$ until RNA isolation by using TRIzol reagent (Invitrogen) according to manufacturer's instructions. RNA concentration was determined by spectrophotometry and quality evaluated by electrophoresis through a $0.8 \%$ agarose gel visualized using Gelstar staining, and capillar electrophoresis (2100 Bioanalyzer; Agilent Technologies, Santa Clara, CA). For semi-quantitative RT-PCR, the reaction was performed on $100 \mathrm{ng}$ of total RNA using the GenAmp thermostable RNA RT-PCR Kit (Applied Biosystems, Foster City, CA). ADAM-12 forward and reverse primers were designed as follows: forward 5'-TTGGCTTTGGAGGAAGCACAGA-3', reverse 5'-TTG AGGGGTCTGCTGATGTCAA-3' using the actin gene (see Table E1 in the online supplement for the primer sequence) as a reference to normalize the quantity of mRNA in each sample. Samples were separated by acrylamide gel electrophoresis and stained with Gel Star (Cambrex, Verviers, Belgium).

Retro-transcription and quantitative real-time PCR were performed using SuperScript Platinum SYBR Green Two-Step qRT-PCR Kit with ROX (Invitrogen) according to manufacturer's instructions. To obtain a normalized target value, actin gene was used as control. Forward and reverse primers for ADAM-10, -12, and -17, CXCL1, CXCL2, CXCL5, CD47 and actin (used as a reference) were designed with Primer Express software (Applied Biosystems). Their sequences were reported in Table E1. 
Results were expressed as the mean \pm SEM of net gene expression $\left(\Delta \mathrm{Ct}_{\text {gene of interest }}-\Delta \mathrm{Ct}_{\mathrm{actin}}\right)$ or relative gene expression expressed in folds $\left(2^{-(\Delta \Delta \mathrm{Ct})}\right)$ compared with unstimulated cells used as calibrator.

\section{Flow Cytometry Analysis}

Epithelial layer of cultured confluent clones was dissociated with PBS + EDTA (5 mM) solution and cells were detached by scraping. Epithelial cells were centrifuged and resuspended in PBS plus $2 \%$ fetal calf serum. After permeabilization with the Perm-Wash kit (BD Biosciences, San Diego, CA) or not, cells were incubated with rabbit IgG antiADAM-12 (N-terminal domain) or normal rabbit $\mathrm{IgG}(2 \mu \mathrm{g} / \mathrm{ml}$; Abcam). After washing, antibody binding was detected with phycoerythrin (PE)-conjugated goat IgG anti-rabbit IgG (Invitrogen). Concerning the adhesion molecules, the following $\mathrm{mAb}$ were used: fluoresceine (FITC)-conjugated anti-CD49c ( $\alpha 3$-integrin, clone 17C6; ABD Serotec, Oxford, UK), PE-conjugated anti-CD29 ( $\beta 1$-integrin, clone MAR4), anti-CD54 (ICAM-1, clone HA58), PE-Cy5-conjugated anti-CD49 d ( $\alpha 4$-integrin, clone 9F10) and unlabeled anti-CD49f $(\alpha 6-$ integrin, clone NKI GOH3; BD Biosciences), anti-CD51 ( $\alpha \mathrm{v}$-integrin, clone AV1), and anti-CD104 ( $\beta 4$-integrin, clone ASC3; Chemicon, Temecula, CA) $\mathrm{mAb}$ and the corresponding isotype controls. Mouse IgG mAb anti-SIRP $\alpha$ (SE7C2; Santa Cruz Biotechnology, La Jolla, $\mathrm{CA}$ ), anti-CD47 (clone B6H12; BD Biosciences) and anti-EGFR (MAB126; Chemicon) were also used in this study. Binding of unlabeled $\mathrm{mAb}$ was detected by addition of PE-conjugated anti-mouse or anti-rat IgG rabbit IgG (Southern Biotechnology, Birmingham, AL). Then, cells were washed, fixed with paraformaldehyde (PFA) in PBS, and 5,000 events were analyzed on a FACScalibur flow cytometer with CellQuest software (Becton Dickinson, Pont de Claix, France). Results are expressed as the difference between median fluorescence intensity (MFI) with specific antibody minus the isotype control MFI $(\Delta \mathrm{MFI})$.

\section{Chemokine Measurement}

The concentration of human CXCL8/IL-8 and CXCL1/GRO- $\alpha$ was determined in clone cell supernatants collected after 8 hours or 24 hours by sandwich enzyme-linked immunosorbent assay (R\&D Systems, Abingdon, UK) as described by the manufacturer. Protein content of cell lysates was determined using the Bradford method (Bio-Rad, Hercules, CA) and results were expressed as $\mathrm{pg} / \mu \mathrm{g}$ of total protein when necessary.

\section{ADAM-12 Transfected Clones Adhesion and Migration Assay}

To assess ADAM-12 transfected clones adhesion, 96-well plates coated with collagen G (Biochrom) or fibronectin $\left(2.5 \mu \mathrm{g} / \mathrm{cm}^{2}\right.$; Sigma) as substrates were preincubated with bovine serum albumin $(0.5 \%$ in PBS for $30 \mathrm{~min}$ ). BV27, BA17 and BA36 clones were plated for 1 hour at $37^{\circ} \mathrm{C}$. After rinsing with PBS, the number of adherent cells was quantified by MTT assay (Roche, Penzberg, Germany) according to the manufacturer's instructions. Optical density was read at $570 \mathrm{~nm}$. Results are expressed as the mean \pm SEM of number of adherent cells.

We evaluated the ADAM-12 transfected clones ability to migrate by Wound Healing Assay. For this, confluent clones grown onto collagen $\mathrm{G}$ or fibronectin-coated plates were scratch wounded and pictures were taken at $0,12,24,36$, and 48 hours. Wound healing rate was determined by quantifying the cell-free surface inside the wound. Results are expressed as the percent of cell-free surface at each time point, considering the time point 0 as $100 \%$.

\section{Neutrophil Chemotaxis, Adhesion, and Migration Assays}

Chemotaxis was performed in 48-well Boyden microchamber (NeuroProbe, Gaithersburg, MD). The lowest well was filled with supernatant from clones (1/10 in RPMI medium), recombinant human CXCL8 (200 ng/ml; R\&D Systems) or with medium (RPMI 1640; Invitrogen). Each condition was performed in triplicate. The chamber was covered with a polycarbonate membrane of a $3-\mu \mathrm{m}$ pore size. Then, neutrophil suspension in RPMI $1640\left(45 \mu \mathrm{l}\right.$ at $1 \times 10^{6}$ cells $\left./ \mathrm{ml}\right)$ was added to each well of the upper chamber. After incubation for 30 minutes at $37^{\circ} \mathrm{C}$, cells that passed trough the membrane were fixed in methanol and stained with May Grünwald Giemsa. Membranes were mounted and four fields per well were counted. Neutrophil chemotactic activity is expressed as mean neutrophil number observed for each clones supernatant condition minus the mean neutrophil number observed from RPMI alone condition. To define the implication of chemokines in neutrophil recruitment, we preincubated for 1 hour, supernatants from BA clones or as a control, CXCL1 and CXCL8 solution at $100 \mathrm{ng} / \mathrm{ml}$ with neutralizing monoclonal antibodies against human CXCL1 and CXCL8 $(10 \mu \mathrm{g} / \mathrm{ml}$; R\&D Systems).

To test the neutrophil adhesion, clones were seeded in a 96-well plate until confluence. Purified neutrophils resuspended in HBSS (Hanks' balanced salt solution; Invitrogen) were added either onto clones $(2 \times$ $10^{5}$ per well or at growing known concentrations) or onto plastic plates and incubated for 1 hour at $37^{\circ} \mathrm{C}$. In the case of attachment to plastic, HBSS or supernatants collected from clones (stimulated or not with $20 \mathrm{ng} / \mathrm{ml} \mathrm{TNF} \alpha$ for $1 \mathrm{~h}$ ) were added to neutrophils. After incubation, plates were rinsed in PBS and cells were lysed in LBH and then frozen and thawed twice. The number of adherent neutrophils was quantified by their peroxydase activity with OPD (o-Phenylenediamine dihydrochloride; Sigma). Results are expressed as numbers of neutrophils that remained attached. To rule out the possibility that ADAM-12 could cleave the CD47 receptor SIRP- $\alpha$ (SIRP-1) present on neutrophils, we measured its membrane expression after neutrophil adhesion onto BEAS-2B cells or ADAM-12-overexpressing clones (stimulated or not with $20 \mathrm{ng} / \mathrm{ml} \mathrm{TNF-} \alpha$ ). Quantification was performed by flow cytometry as described above using a mouse IgG mAb anti-SIRP- $\alpha$ (Santa Cruz Biotechnology).

Migration assays were performed using 3- $\mu \mathrm{m}$-pore Transwell inserts that were coated on the lower side with collagen G. Clones were loaded onto this side, and after they reached confluence, they were stimulated or not with TNF- $\alpha$ (20 ng/ml; Peprotech) added in the lower chamber. Purified neutrophils in HBSS $\left(1 \times 10^{6}\right)$ were loaded on the upper chamber and incubated for 1 or 2 hours at $37^{\circ} \mathrm{C}$. After incubation, neutrophils were recovered from loading compartment, which contains cells that did not migrate, from epithelial cells layer and from the lower chamber with neutrophils that migrated. A known number of neutrophils followed the same process to be used as reference. After lysis in LBH, cells were frozen and thawed twice and loaded onto a 96-well plate for detection. The number of neutrophils was quantified by their peroxydase activity with OPD (o-Phenylenediamine dihydrochloride; Sigma). Results are expressed as the \% of neutrophils that migrated toward the lower chamber from the total of neutrophils recovered.

\section{Statistical Analyses}

Statistical analysis was performed with Graph Pad Prism 4.03. Population differences were evaluated by two-sided Student's $t$ test or for multiple comparisons, one-way ANOVA followed by Turkey test, or Kruskal-Wallis Test followed by Dunn's Multiple Comparison Test when corresponded, according to the experiment and to the distribution of the data. Results are expressed as mean \pm SEM. A $P<0.05$ was considered significant and $P<0.001$ to be highly significant

\section{RESULTS}

ADAM-12 Expression Is Increased in Airway Epithelial Cells by Allergen Challenge in Patients with Allergic Rhinitis

ADAM-12 production was evaluated in nasal biopsy sections from patients with allergic rhinitis or from control subjects obtained at baseline and after allergen challenge. In contrast to control subjects, patients with allergic rhinitis developed a dual clinical response and inflammation within nasal tissue. At baseline, the expression of ADAM-12 was detectable by immunohistochemistry in the upper layer of AEC both in control subjects and in patients with allergic rhinitis, and no difference was detected between both groups (Figures 1A and 1C, respectively). After allergen challenge, an increase of ADAM-12 synthesis in AEC was observed in control subjects (Figure 1D) $(10.9 \pm 1.5$ and $24.7 \pm 2.6 \%$ of positive AEC, before and after allergen challenge, respectively). For patients with allergic rhinitis, a strong increase of ADAM-12 expression was observed in the different layers of AEC $(21.1 \pm 1.7$ and $59.5 \pm$ $12.7 \%$ of positive AEC, before and after allergen challenge, respectively) and also in some vascular sections (Figures $1 \mathrm{E}$ and $1 F$ ). No staining was detected with the isotype control (Figure 1B). 


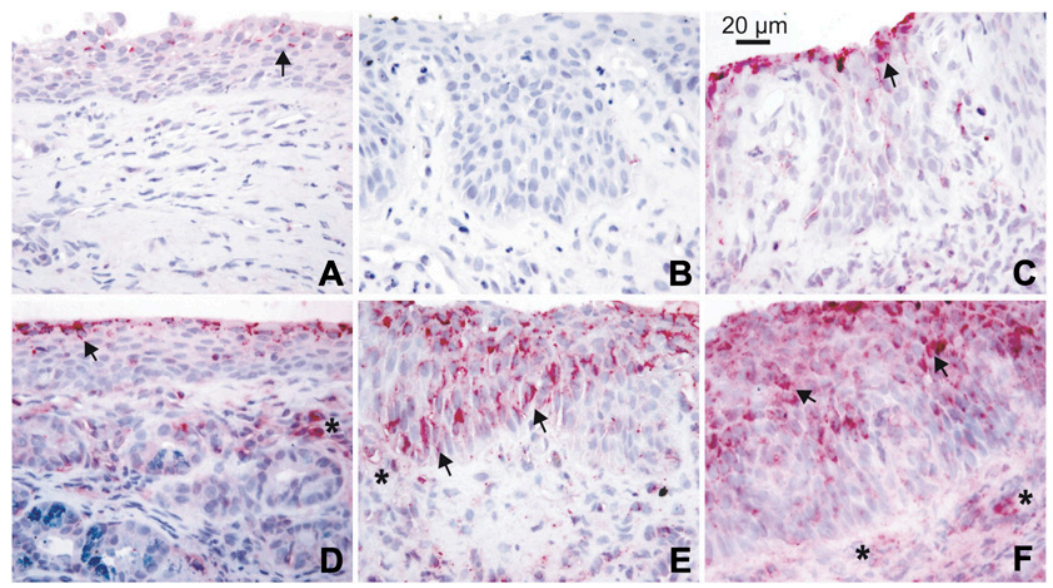

Figure 1. A Disintegrin and Metalloprotease (ADAM)-12 expression in nasal biopsies from $(A$ and $D$ ) healthy individuals and $(B, C, E$, and $F)$ allergic patients before $(A, C)$ and after exposure to the allergen Dpt $(B, D-F)$. Positive staining was detected in red and sections were counterstained with hematoxylin. ADAM-12 expression in epithelial cells (black arrows) and vascular wall (asterisks) was increased in allergic patients after allergen challenge compared with control subjects. No staining was detected with the nonimmune rabbit IgG (B); (magnification: $\times 500)$.

\section{Cytokines Modulate ADAM-12 Production in Bronchial Epithelial Cells and in ADAM-12-Overexpressing Clones}

To identify the potential factors implicated in ADAM-12 overexpression during the allergic reaction, we measured mRNA and protein expression in primary culture of AEC or BEAS-2B cell line in the presence of TNF $\alpha$, IL- 4 and IL-13. Treatment with TNF- $\alpha$ markedly enhanced the mRNA expression for ADAM-12 in AEC primary culture, with a maximal activity at 24 hours (Figure 2A). Similar results were obtained in BEAS-2B cells. Quantification of the mRNA performed by qRT-PCR revealed that TNF- $\alpha$ stimulation at a dose of 20 and $50 \mathrm{ng} / \mathrm{ml}$ for 24 hours enhanced by 3 - to 4-folds the mRNA expression for ADAM-12 (Figure 2B, $P<0.01$ versus unstimulated cells). Moreover, IL-4 and IL-13 (Figure 2B) but not IFN- $\gamma$ (data not shown) amplified the effect of TNF- $\alpha$, whereas alone, they did not significantly enhance the ADAM-12 expression. In parallel, we tested the modulation of other HB-EGF sheddases (ADAM-10 and -17) in AEC. Our data revealed that activation by these cytokines did not modulate the mRNA expression of both metalloproteases (Figure E1A). Evaluation by flow cytometry after intracellular immunostaining showed that 24 hours of incubation with TNF- $\alpha$ also increased ADAM-12 synthesis (Figure 2C, $P<$ $0.05)$.

To define the effect of ADAM-12 overexpression, we selected ADAM-12-overexpressing clones (termed BA17 and BA36) and the control clone transfected with empty vector termed BV27, which were previously characterized (18). At baseline, ADAM12 mRNA expression in BA17 and BA36 was 20 times higher than in the control clone $(18)(P<0.001$; Figure 2D). Nevertheless, activation by TNF- $\alpha$ enhanced the mRNA level in BV and BA clones with a difference of approximately 2 to 3 times $(P<0.001)$. Protein expression was also enhanced with the same range in BA clones compared with BV27 (not shown). There is no difference between the BV27 clone and the BEAS-2B cells concerning the expression of ADAM-12 either at baseline or after activation with TNF- $\alpha$ (data not shown). The ADAM-10 and -17 mRNA expression was similar at baseline in BA17 and BA36 clones as compared with BV27 and BEAS-2B cells, and did not change after stimulation with TNF- $\alpha$ (Figure E1B).

\section{ADAM-12 Overexpression Regulates Integrin Expression and Epithelial Cell Adhesion and Migration}

We first evaluated the expression of integrins and the cell adhesion to extracellular matrix (ECM) components in unstimulated and in TNF- $\alpha$-activated clones. As shown in Figure 3A, overexpression of ADAM-12 gene significantly increased the expression of $\alpha 3$ and $\alpha 4$ integrins in both conditions. Integrins $\alpha \mathrm{V}$, $\alpha 6, \beta 1, \beta 3$, and $\beta 4$ were also measured, and no modulation was observed (data not shown).

Cell adhesion to collagen $\mathrm{G}$ and to fibronectin was determined for clones. As shown in Figure 3B, clones BA17 and BA36
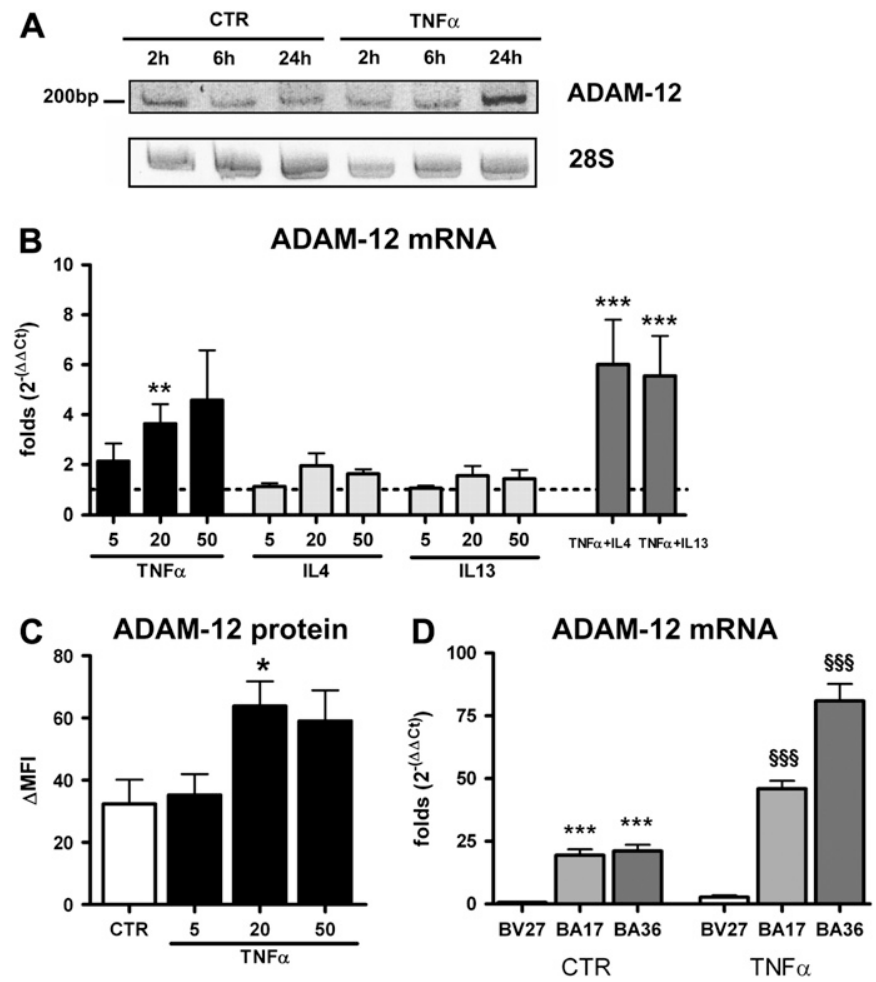

Figure 2. ADAM-12 mRNA expression is increased in airway epithelial cells (AEC) after stimulation. (A) AEC primary culture stimulated for 2, 6 , or 24 hours with TNF- $\alpha$ were analyzed by semiquantitative PCR. (B) Expression of ADAM-12 mRNA in BEAS-2B cell line detected by quantitative RT-PCR after 24 hours of stimulation with TNF- $\alpha$, IL-4, or IL-13. qRT-PCR results are expressed in folds versus nonstimulated control corresponding to the value of 1 . Bars represent the mean \pm SEM $(n=5),{ }^{* *} P<0.01 ;{ }^{* * *} P<0.001$ compared with CTR (cells in medium alone). (C) Flow cytometry analysis of ADAM-12 in BEAS-2B after 24 hours of stimulation with TNF- $\alpha$. Bars show the mean \pm SEM $(n=4)$ of the difference between median fluorescence intensity with the specific antibody minus the isotype control MFI $(\triangle \mathrm{MFI}) .{ }^{*} P<0.05$ compared with CTR. (D) ADAM-12 mRNA expression in BA and BV clones in CTR and after 24 hours of stimulation with TNF- $\alpha$. Bars represent the mean $\pm \operatorname{SEM}(n=5),{ }^{* * *} p<0.001$ compared with BV27 CTR; $\S \S \$<0.001$ versus BA17 and BA36 CTR. 

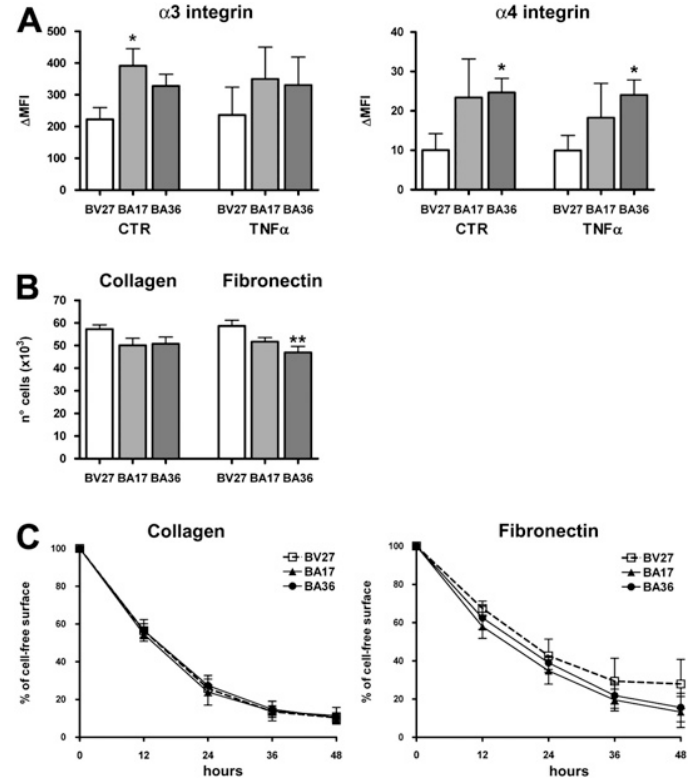

Figure 3. ADAM-12 overexpression modulates integrin expression and cell adhesion and migration. (A) Flow cytometry analysis of $\alpha 3$ integrin and $\alpha 4$ integrin protein expression in ADAM-12-overexpressing clones in CTR and after 24 hours of stimulation with TNF- $\alpha$. Graphs show the mean \pm SEM of $\Delta$ MFI $(n=10),{ }^{*} p<0.05$ versus BV27. (B) Cell attachment to collagen or fibronectin matrix is reduced in ADAM-12overexpressing clones $(n=7)$, ${ }^{* *} P<0.01$ BA36 versus BV27. (C) Wound Healing Migration Assay onto collagen or fibronectin substrates. Plots show the mean \pm SEM of the $\%$ of ADAM-12 clones-free surface at different time points $(n=5)$.

displayed a reduced adhesion to fibronectin as compared with BV27 clone, but the difference was significant only for BA36 (Figure 3B, $P<0.01$ ).

To complete this approach, kinetics of cell migration in a wound-healing assay was determined for these clones on the same ECM components. Our data showed that the stripped surface was almost totally covered after 48 hours of incubation in BV27 cells as well as in BA clones (Figure 3C) and BEAS-2B cells (data not shown) cultured on collagen G. Onto fibronectin, the wound healing for BV27 clones was incomplete at 48 hours, remaining at approximately $30 \%$ of cell-free surface, whereas it was approximately at $15 \%$ in both BA clones (Figure 3C).

These data show that the up-regulation of ADAM-12 in bronchial epithelial cells leads to an increased expression of certain $\alpha$-integrins and to the modulation of cell attachment and migration on fibronectin but not on collagen $\mathrm{G}$.

\section{ADAM-12 Overexpression Increases CXCL1 and CXCL8 Secretion and Neutrophil Recruitment}

An important function of AEC is to control the local inflammatory reaction through its response to danger signal by secreting chemokines such as CXCL8 able to induce granulocyte recruitment (27). To assess potential involvement of ADAM-12 in this process, we first focused on CXCL8 secretion by BA clones. As shown in Figure 4A, CXCL8 was enhanced in unstimulated BA36 compared with the control clone BV27 $(P<0.05)$. A similar tendency was observed in TNF- $\alpha$-activated BEC (Figure 4A). To define the implication of other chemokines active on neutrophils, the expression of CXCL1, CXCL2, and CXCL5 was first evaluated by qRT-PCR. While CXCL2 and CXCL5 were not modulated, the mRNA expression for CXCL1 was markedly increased in BA clones in comparison to BV27 cells (3-fold increase; data
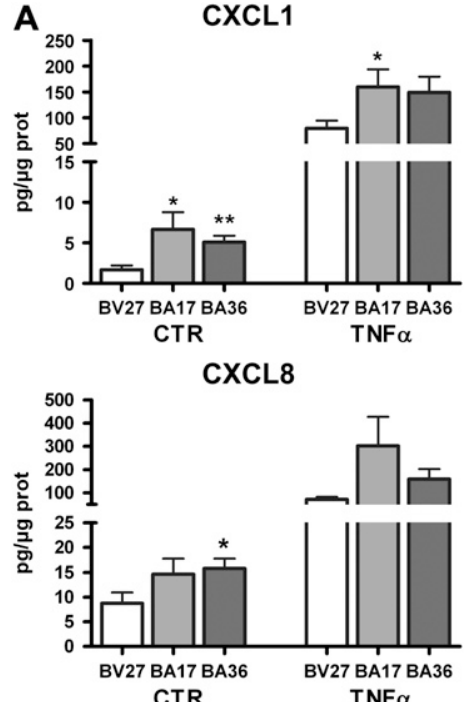

Figure 4. (A) $\mathrm{CXCL1}$ and CXCL8 secretion from supernatants of clones stimulated or not with TNF $\alpha$ for $24 \mathrm{~h}$ determined by enzyme-linked immunosorbent assay (ELISA). Values represent the mean \pm $\operatorname{SEM}(n=4-6),{ }^{*} p<0.05$ and $* * P<0.01$ versus BV27. (B) Neutrophil recruitment by supernatants from ADAM-12overexpressing clones stimulated or not with TNF- $\alpha$ for 24 hours was determined after migration in a micro-chemotaxis chamber. Values represent the mean \pm SEM of the number of neutrophils migrated $(n=5), * P<0.05$ versus respective $\mathrm{BV} 27$.

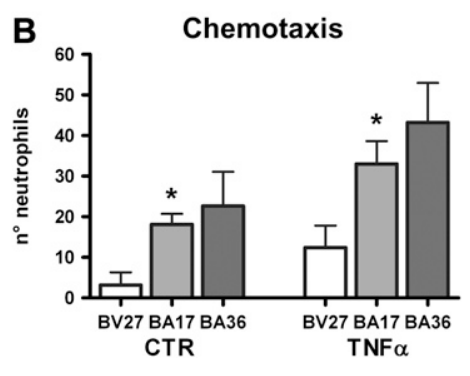

not shown). At the protein level, the secretion of CXCL1 was increased in unstimulated $(P<0.05)$ and TNF- $\alpha$-activated $(P<$ 0.05 only for BA17 cells) BA17 and BA36 clone in comparison with BV27 cells in the same culture condition (Figure 4A).

We also measured the chemotactic effect of these supernatants on neutrophils. Supernatants were obtained after 24 hours of incubation of clones under control or TNF- $\alpha$ stimulation. As expected, TNF- $\alpha$ activation of BV27 clone increased the number of recruited neutrophils in comparison with unstimulated condition. Supernatants of unstimulated and TNF$\alpha$-activated BA17 and BA36 clones collected at 24 hours induced an increase of neutrophil recruitment (Figure 4B, $P<$ 0.05 for BA17) compared with BV cells. To determine the role of CXCL1 and CXCL8 in this effect, we preincubated the supernatants of BA clones with neutralizing anti-CXCL8 and anti-CXCL1 antibodies. Neutralization of CXCL8 did not affect the neutrophil recruitment induced by the clones $(20 \%$ decrease), whereas this treatment inhibited the effect of rh-CXCL8 (78.8\% decrease). In contrast, neutralization of CXCL1 significantly decreased the effect of BA17 and BA36 clones by $52 \%$, and it diminished the rh-CXCL1 activity by $72 \%$.

These data show that ADAM-12 overexpression in BEAS$2 \mathrm{~B}$ cells increases the secretion of CXCL1 and CXCL8 as well as the capacity to recruit neutrophils. Our data strongly suggest that CXCL1 has a major role in this activity in contrast to CXCL8.

\section{ADAM-12 Overexpression Modulates CD47 Expression, Neutrophil Adhesion, and Transepithelial Migration}

The transepithelial migration of neutrophils is a multi-step process that involves different adhesion molecules expressed by epithelial cells, such as ICAM-1 and the integrin-associated protein CD47. To elucidate the mechanism of ADAM-12 action 
on neutrophil recruitment, we measured the levels of ICAM-1 and CD47 expression in clones overexpressing ADAM-12. As expected, treatment with $\mathrm{TNF}-\alpha$ significantly enhanced the membrane expression of ICAM-1 in all clones $(P<0.001)$, although its level was similar in BA and BV clones in either unstimulated or in TNF- $\alpha$-activated cells (Figure 5A). In contrast, CD47 membrane expression and mRNA levels were significantly lower in BA clones compared with BV27 or to BEAS-2B cells at baseline (Figure 5B, $P<0.01$ and $P<0.05$, respectively). TNF- $\alpha$ stimulation significantly increased CD47 protein and mRNA expression in BA clones (Figure 5B, $P<$ $0.05)$. It has been previously observed that the interaction between epithelial CD47 and its counterreceptor signal regulatory protein (SIRP- $\alpha$ ) regulates adhesive signaling processes (28) and enhances the rate of transepithelial migration of neutrophils (29). Considering this, we determined the ability of neutrophils to attach to clones and to migrate through a confluent epithelium. ADAM-12 overexpression led to an inhibition of neutrophil attachment to these cells compared with BV27 (Figure 5C, $P<$ $0.05)$. To rule out the possibility that ADAM-12 might shed the extracellular domain SIRP $\alpha$ on neutrophils and thus contribute to regulate $\mathrm{CD} 47-\mathrm{SIRP} \alpha$ interaction, we measured the expression of SIRP- $\alpha$ in neutrophils by flow cytometry after a neutrophil adhesion assay onto AEC. We observed that incubation of neutrophils with BEAS-2B cells significantly enhanced membrane SIRP- $\alpha$ expression $(P<0.01$; Figure E2). However, the level of SIRP- $\alpha$ on granulocytes incubated with BA17 and BA36 clones was not significantly different from that observed in presence of BEAS-2B or in BV27 cells.

Analysis of neutrophil transepithelial migration in Transwell inserts showed that TNF- $\alpha$ stimulation for 1 (Figure E3) and 2 hours increased migration at similar levels in all clones, with a maximal effect at 2 hours (Figure 5D). However, the number of neutrophils migrating through the unstimulated confluent epithelium of BA clones was slightly reduced as compared with BV27 $(P=$ NS).

Our results indicate that ADAM-12 overexpression in epithelial cells decrease neutrophils attachment to BA clones and decrease CD47 expression, which can possibly affect transepithelial passage.

\section{ADAM-12 Overexpression Mediates the CXCL1, CXCL8, and CD47 Expression via EGFR}

Considering that one of the well-known functions of ADAM-12 is the shedding of the EGFR ligand Pro HB-EGF (17), and that secretion of mature HB-EGF was increased in BA as compared with BV clones (18), we tested the hypothesis that ADAM-12 affects the epithelial functions through the transactivation of this receptor.

For this purpose, we determined the membrane expression of EGFR in clones. We found that EGFR expression in BA or $\mathrm{BV}$ clones or BEAS-2B did not vary in either unstimulated or TNF- $\alpha$-stimulated conditions (Figure 6A and data not shown).

We analyzed the capacity of the EGFR inhibitor AG1478 to reverse the effects of ADAM-12 overexpression. Treatment of the clones with AG1478 during 24 hours did not affect the increased expression of $\alpha 3$ and $\alpha 4$ integrins previously observed (Figure 6B). In contrast, AG1478 markedly inhibited the synthesis of CXCL1 and CXCL8 by BA17 $(P<0.05)$ or BA36 $(P=\mathrm{NS})$ clone (Figure 6C), whereas it had no effect on BV27 cells. However, AG1478 did not reverse the inhibitory effect of ADAM-12 overexpression on CD47 protein expression (Figure 6D).

We also measured the effect of EGF on the same parameters in BEAS-2B cells. The $\alpha 3$-integrin expression was significantly increased after EGF stimulation (Figure 7A, $P<0.05$ ). This EGF
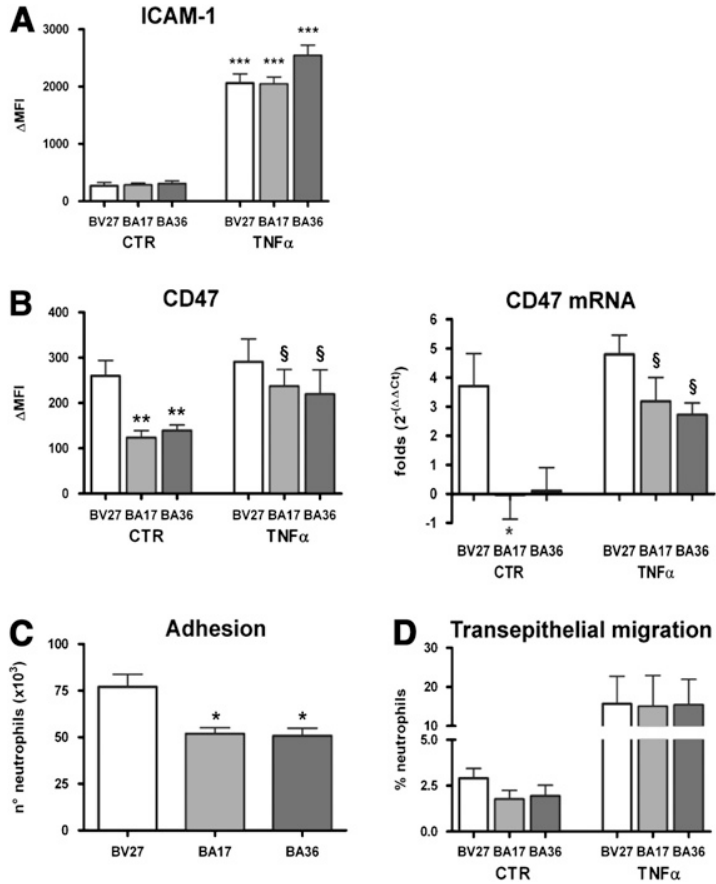

Figure 5. (A) ICAM-1 protein expression analyzed by flow cytometry in BA and BV clones after 24 hours of stimulation with TNF- $\alpha$. Graphs report the mean \pm SEM of $\Delta \mathrm{MFI}(n=4-6),{ }^{* * *} P<0.001$ versus CTR. (B) CD47 protein expression analyzed by flow cytometry and CD47 mRNA expression determined by real-time quantitative qRT-PCR in clones after stimulation with TNF- $\alpha$ for 24 hours; $* P<0.05$ and $* * P<$ 0.01 versus $B V 27$ CTR; $\$ P<0.05$ versus BA17 and BA36 CTR. (C) Effect of ADAM-12 overexpression on neutrophil adhesion onto clones. Graph shows the mean \pm SEM of the numbers of neutrophils that remained attached after 1 hour of incubation $(n=4)$, ${ }^{*} P<0.05$ versus BV27. (D) Neutrophil transepithelial migration through a confluent epithelium of BA and BV clones activated or not by TNF- $\alpha$ for 2 hours. Bars represent the mean \pm SEM of the percent of neutrophils that migrated from total recovered in all compartments $(n=4)$.

effect was totally blocked by pre-treatment with the EGFR inhibitor AG1478 $(P<0.05$; Figure 7A). Conversely, no significant effect was observed for the expression of $\alpha 4$-integrin (Figure 7A). The addition of EGF to BEAS-2B cells strongly upregulated CXCL1 and CXCL8 levels (Figure 7B, $P<0.05$ and $P<0.001$, respectively) and the inhibitor AG1478 neutralized this effect (Figure 7B, $P<0.01$ and $P<0.001$, respectively). CD47 expression was significantly inhibited after stimulation with EGF (Figure 7C, $P<0.05$ ), whereas the addition of AG1478 plus EGF significantly increased its expression (Figure 7C, $P<$ 0.001).

In summary, ADAM-12 overexpression probably induced EGFR transactivation, which is implicated at least in part in the regulation of $\alpha 3$ integrin and CD47 expression as well as in CXCL1 and CXCL8 production.

\section{DISCUSSION}

In this study we report that ADAM-12 expression is strongly increased in airway epithelial cells from patients with allergic rhinitis after allergen challenge. In vitro, TNF- $\alpha$ stimulation also induces the up-regulation of ADAM-12 in AEC and BEAS-2B cells. Based on these results, we analyzed the effect of ADAM-12 overexpression on AEC functions. Our data show that AEC transfection with a plasmid expressing ADAM-12 affects the expression of integrins, cell adhesion, and migration, as well 

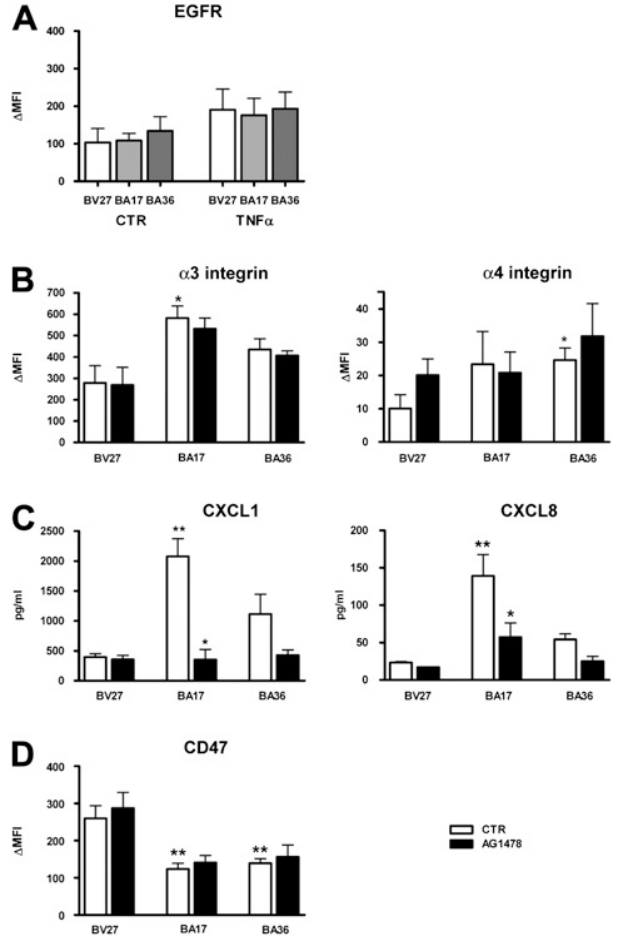

므 ${ }_{\text {AG1478 }}^{\text {CTR }}$

Figure 6. (A) Epidermal growth factor receptor (EGFR) protein levels analyzed by flow cytometry after 24 hours of stimulation with TNF- $\alpha$. Data are expressed as the mean \pm SEM of $\Delta \mathrm{MFI}(n=4)$. (B) $\alpha 3$ and $\alpha 4$ integrins and $(D) C D 47$ protein expression analyzed by flow cytometry after 24 hours of treatment with AG1478 of unstimulated and TNF$\alpha$-activated clones. Bars show the mean \pm SEM of $\Delta \mathrm{MFI}(n=4-5)$, ${ }^{*} P<0.5$ and ${ }^{* *} P<0.01$ versus BV27 CTR. (C) CXCL1 and CXCL8 secretion determined by ELISA in cell supernatants from clones in the same conditions as reported in $B$. Values represent the mean \pm SEM $(n=4),{ }^{*} p<0.01$ versus CTR and ${ }^{* *} p<0.01$ versus BV27.

as their capacity to secrete chemokines and to recruit neutrophils.

Allergen exposure of patients with allergic rhinitis increases the production of ADAM-12 in nasal epithelium and endothelium. Since we demonstrated a direct effect of TNF- $\alpha$ on AEC, TNF- $\alpha$ may be implicated in the increased expression of this metalloprotease during the allergic reaction $(23,24)$, Interestingly, the Th2 cytokines IL-4 and IL-13 amplify the ADAM-12 expression induced by TNF- $\alpha$ in airway epithelium, probably explaining the enhanced level observed in the patients with allergic rhinitis. Since these cytokines are involved in allergic asthma (1) and affect the production of ADAM-12 in primary culture of bronchial epithelial cells, allergic asthma is probably associated with an increased synthesis of this metalloprotease. Another argument is raised by the fact that an increased expression of ADAM-12 mRNA was detected in induced sputum from patients with allergic asthma (10).

Our goal was then to determine the consequence of ADAM12 overexpression in AEC. We previously showed that cells overexpressing ADAM-12 display increased proliferation rates and are protected against etoposide-induced apoptosis (18). In the present study, we have first analyzed the consequences of ADAM-12 overexpression on cell migration and adhesion. In contrast to $\beta$ integrins, $\alpha 3$ and $\alpha 4$ integrins were significantly overexpressed on cell membranes by the up-regulation of ADAM-12, although no effect was detected at the level of mRNA expression (data not shown). Therefore, these results are in agreement with the concept of ADAMs affecting the
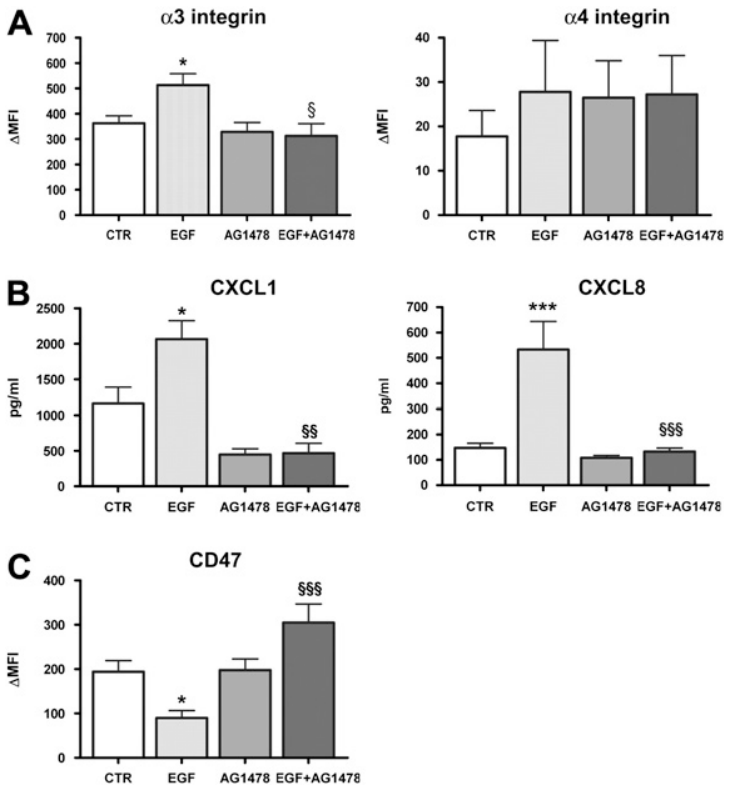

Figure 7. Modulation by EGFR activation of BEAS-2B cell function. ( $A$ ) Flow cytometry analysis of $\alpha 3$ integrin and $\alpha 4$ integrin protein expression after 24 hours of stimulation with EGF, AG1478, or both EGF and AG1478. Graphs show the mean \pm SEM of $\Delta \mathrm{MFI}(n=7)$, ${ }^{*} P<$ 0.05 versus CTR and $\$ P<0.05$ versus EGF. $(B)$ CXCL1 and CXCL8 secretion determined in cell supernatants in the same conditions as described in $A$. Values represent the mean $\pm \operatorname{SEM}(n=5-9)$, * $P<0.05$ and ${ }^{* * *} P<0.001$ versus CTR; $\$ \S P<0.01$ and $\$ \S \S P<0.001$ versus EGF. (C) CD47 protein expression analyzed by flow cytometry in BEAS-2B cells incubated in the same conditions as described in $A$. Graph shows the mean \pm SEM of $\Delta \mathrm{MFI}(n=6),{ }^{*} P<0.05$ versus CTR and $\$ \S \S P<$ 0.001 versus EGF.

surface localization of integrin (19). It has been shown that $\alpha 3$ / $\beta 1$ and $\alpha 4 / \beta 1$ integrins bind to the major constituents of the basal membrane like collagen and to ECM proteins such as fibronectin, which are found to be increased during inflammation (30). Adhesion experiments showed that ADAM-12overexpressing clones adhere with a lower intensity onto fibronectin. Considering that $\beta 1$ integrin levels were not modified, these results indicate that $\alpha 3$ and $\alpha 4$ might not have a major role in the cell adhesion onto this substrate. Another hypothesis is that the increased membrane expression of these integrins was not associated with an increased functionality. Moreover, it has been reported that ADAM-12 expression can moderately increase cell adhesion to fibronectin, although this effect is not specific to $\alpha 4 / \beta 1$ integrin (31). Whether ADAM-12 up-regulation also affected the expression of surface glycoproteins involved in adhesion to fibronectin remains to be determined. Interestingly, re-epithelialization in a wound healing assay was slightly faster onto fibronectin matrix in ADAM-12overexpressing clones. Some possible explanations include in one hand, the increase in proliferation rate and on the other hand, the modulation of integrin expression. The fact that ADAM-12 increases cell proliferation suggests that its effect on re-epithelialization may be due to an accelerated cell division (18). Moreover, in vivo, re-epithelialization depends on rapid migration of epithelial cells over the injured area (31, 32) and on the expression of $\alpha 2, \alpha 3$, and $\alpha 6$ integrins (33). Interestingly, ADAM-12 overexpression increased the level of $\alpha 3$ integrin, which can selectively influence cell migration.

During lung inflammation, airway epithelial cells produce several interleukins and chemokines leading to leukocyte re- 
cruitment toward the site of injury $(27,34)$. At baseline and in TNF- $\alpha$-stimulated conditions, bronchial epithelial cells overexpressing ADAM-12 secrete higher levels of CXCL1 and CXCL8 associated with an increased recruitment of neutrophils. As shown by neutralization experiments, CXCL8 is not mainly involved in the modulation of neutrophil migration, whereas CXCL1 plays an essential role at least in vitro. We cannot exclude that in vivo, CXCL8 or other chemoattractants may interfere with CXCL1. In addition, BA clones secreted significantly higher levels of CCL5/RANTES involved in the recruitment of monocytes, $\mathrm{T}$ cells, and eosinophils (data not shown). Neutrophil transepithelial migration requires the involvement of adhesion molecules, including ICAM-1 and CD47, to facilitate neutrophil attachment and migration (35). ICAM-1 protein is up-regulated in airway epithelium in response to inflammatory mediators (36) and localizes at the apical region of cell boundaries (37). Under these conditions, the migrating front of a neutrophil within the epithelial paracellular space binds to ICAM-1 (29). However, there was no difference in ICAM-1 expression between BA and $\mathrm{BV}$ clones, although TNF- $\alpha$ stimulation induced a significant increase of ICAM-1 expression. Whether ADAM-12 is implicated in its redistribution within the epithelium remains to be determined.

CD47 is a penta-transmembrane protein highly expressed in most cell types, including epithelial cells. It colocalizes with Ecadherin and ZO-1 at cell-cell adhesion sites and participates to the regulation of cell adhesion and migration through reorganization of the actin cytoskeleton (38). During leukocyte transmigration, CD47 regulates the rate of PMN transepithelial migration but does not affect initial adhesion events $(35,39)$. In vitro, $\mathrm{PMN}$ migration across epithelial cell monolayers deficient in CD47 was significantly increased after stable transfection with CD47 (39). Although the mechanisms of how CD47 regulates neutrophils transepithelial migration and epithelial cell responses during transmigration are not elucidated (29), it is known that CD47 associates with a number of molecules, including some integrins and signal regulatory protein (SIRP) $\alpha$ (SHP substrate- 1 or SHPS-1) (39). SIRP $\alpha$, which is present at high levels on neutrophils $(28,40)$, facilitates the neutrophil progression toward the paracellular space (35). Here, we observed that the number of neutrophils that adhere to ADAM-12-overexpressing cells was significantly decreased. This effect was not due to soluble factors because the incubation of neutrophils with supernatant from ADAM-12-overexpressing clones alone or collected after TNF- $\alpha$ stimulation had no effect (data not shown). Interestingly, in ADAM-12-overexpressing cells, CD47 membrane expression and mRNA levels are significantly down-regulated. In addition, the ectodomain shedding of SIRP $\alpha$ is required for cell migration (41) and is blocked by a metalloprotease inhibitor KB-R7785, which has been shown to neutralize ADAM-12-mediated ectodomain cleavage of HB-EGF (17). Nevertheless, neutrophil coculture with BA17 and BA36 clones does not reduce the membrane expression of SIRP- $\alpha$ in neutrophils, suggesting that this metalloprotease is not involved in the shedding of SIRP $\alpha$. We also observed that the up-regulation of ADAM-12 induced a decrease in neutrophils transepithelial migration in unstimulated conditions, but not after activation with TNF- $\alpha$. This can be related with the fact that CD47 expression is markedly inhibited in unstimulated BA clones, but is strongly increased after stimulation with this cytokine, although there is still some difference as compared with the BV clones.

Together these results suggest that overexpression of ADAM-12 in AEC increases their neutrophil chemotactic activity, alters their capacity to effectively attach neutrophils, and can lead to a decrease of the transepithelial passage of these latter probably due to the low levels of CD47. Thus, ADAM-12 may target the regulation of initial steps of neutrophil transepithelial migration, adhesion, and migration itself preventing the passage into the paracellular spaces. This negative regulation may be a way to control the PMN rate of access to the epithelium-lumen and may lead to their accumulation within the airway mucosa.

Because we previously found that the BA clones produce high levels of mature HB-EGF (18), we considered a possible involvement of EGFR activation. It has previously been shown that AEC expressed major HB-EGF sheddases, such as ADAM-10 and ADAM-17 (42, 43). Although at baseline the ADAM-12 expression is low compared with ADAM-10 and -17 mRNA levels, ADAM-12 expression is strongly up-regulated in vitro by TNF- $\alpha$. Soluble HB-EGF production by BA clones is approximately 5- to 10-fold increased in comparison to BV27 or BEAS2B cells (18) demonstrating that a 20 -fold increase in the level of ADAM-12 is associated with a very significant increase in the level of HB-EGF. It is also important to underline that the level of ADAM-9 (18), ADAM-10, and ADAM-17 are not differentially expressed in BA17 and BA-36 clones as compared with BV27 and BEAS-2B cells. These data suggest that the TNF- $\alpha-$ and allergeninduced up-regulation of ADAM-12 might be associated with the HB-EGF-mediated EGFR activation. As previously demonstrated, the stimulation of airway epithelial cells with TNF- $\alpha$ causes EGFR expression (44), but the EGFR membrane levels are not increased in BA clones as compared with BV27. By using a pharmacologic inhibitor specific for EGFR, we demonstrated that the increased secretion of CXCL1 and CXCL8 observed in ADAM-12-overexpressing clones was reversed, while $\alpha 3$ and $\alpha 4$ integrins and CD47 were not affected. Using BEAS-2B cells, we show that the stimulation with EGF reproduced the modulation of 2- to 3-fold of $\alpha 3$ integrin expression, secretion of CXCL1 and CXCL8, and CD47 membrane expression observed in ADAM12-overexpressing clones. This effect was reverted by the EGFR inhibitor AG1478 in the case of CXCL1 and CXCL8 confirming the implication of EGFR in the effect of ADAM-12. Previous reports have shown that EGFR transactivation leads to CXCL8 secretion through the mobilization of EGFR/ERK1/2/activating protein-1 pathway (45). Interestingly, AG1478 also blocked the EGF-induced modulation of $\alpha 3$ integrin and CD47. Taking into account the presence of high levels of HB-EGF secreted by ADAM-12-overexpressing clones, it seems highly probable that EGFR receptor is activated by this ligand in BA clones. To explain the discrepancy concerning the $\alpha 3$ integrin and CD47 expression, one might speculate that different pathways are mobilized by ADAM-12 and that the inhibition of EGFR is not sufficient to stop the expression of both molecules. Moreover, considering that we focused on the pharmacologic inhibition of EGFR, it is possible that other receptors, such as erbB4, might be involved in this regulation. Another possibility is that $\alpha 3$ integrin and CD47 expression is less dynamically regulated than the secretion of chemokines, and that the duration of the treatment with AG1478 is not sufficient to obtain a significant effect on these parameters.

Together, these results showed that allergic inflammatory reaction is associated with the production of ADAM-12 within the airway epithelium. The overexpression of ADAM-12 is responsible for the modulation of cell adherence and migration. Moreover, this process is likely to participate in granulocyte recruitment through the production of chemokines and the regulation of adhesion molecules, potentially leading to the accumulation of neutrophils within the airway mucosa. Thus, these data show that ADAM-12 by the modulation of neutrophil migration associated with the transactivation of EGFR may participate in the airway remodeling associated with the allergic reaction. 
Conflict of Interest Statement: None of the authors has a financial relationship with a commercial entity that has an interest in the subject of this manuscript.

\section{References}

1. Bousquet J, Jeffery PK, Busse WW, Johnson M, Vignola AM. Asthma: from bronchoconstriction to airways inflammation and remodeling. Am J Respir Crit Care Med 2000;161:1720-1745.

2. Lamblin C, Gosset P, Tillie-Leblond I, Saulnier F, Marquette CH, Wallaert B, Tonnel AB. Bronchial neutrophilia in patients with noninfectious status asthmaticus. Am J Respir Crit Care Med 1998; 157:394-402.

3. Gosset P, Tillie-Leblond I, Malaquin F, Durieu J, Wallaert B, Tonnel AB. Interleukin-8 secretion in patients with allergic rhinitis after an allergen challenge: interleukin- 8 is not the main chemotactic factor present in nasal lavages. Clin Exp Allergy 1997;27:379388.

4. Vignola AM, Riccobono L, Mirabella A, Profita M, Chanez P, Bellia V, Mautino G, D'Accardi P, Bousquet J, Bonsignore G. Sputum metalloproteinase-9/tissue inhibitor of metalloproteinase-1 ratio correlates with airflow obstruction in asthma and chronic bronchitis. Am J Respir Crit Care Med 1998;158:1945-1950.

5. Mautino G, Oliver N, Chanez P, Bousquet J, Capony F. Increased release of matrix metalloproteinase-9 in bronchoalveolar lavage fluid and by alveolar macrophages of asthmatics. Am J Respir Cell Mol Biol 1997; 17:583-591.

6. Cataldo DD, Tournoy KG, Vermaelen K, Munaut C, Foidart JM, Louis R, Noel A, Pauwels RA. Matrix metalloproteinase-9 deficiency impairs cellular infiltration and bronchial hyperresponsiveness during allergeninduced airway inflammation. Am J Pathol 2002;161:491-498.

7. Cataldo D, Munaut C, Noel A, Frankenne F, Bartsch P, Foidart JM, Louis R. MMP-2- and MMP-9-linked gelatinolytic activity in the sputum from patients with asthma and chronic obstructive pulmonary disease. Int Arch Allergy Immunol 2000;123:259-267.

8. Van Eerdewegh P, Little RD, Dupuis J, Del Mastro RG, Falls K, Simon J, Torrey D, Pandit S, McKenny J, Braunschweiger K, et al. Association of the ADAM33 gene with asthma and bronchial hyperresponsiveness. Nature 2002;418:426-430.

9. King NE, Zimmermann N, Pope SM, Fulkerson PC, Nikolaidis NM, Mishra A, Witte DP, Rothenberg ME. Expression and regulation of a disintegrin and metalloproteinase (ADAM) 8 in experimental asthma. Am J Respir Cell Mol Biol 2004;31:257-265.

10. Paulissen G, Rocks N, Quesada-Calvo F, Gosset P, Foidart JM, Noel A, Louis R, Cataldo DD. Expression of ADAMs and their inhibitors in sputum from patients with asthma. Mol Med 2006;12: 171-179.

11. Blobel CP. ADAMs: key components in EGFR signalling and development. Nat Rev Mol Cell Biol 2005;6:32-43.

12. Porter S, Clark IM, Kevorkian L, Edwards DR. The ADAMTS metalloproteinases. Biochem J 2005;386:15-27.

13. Gilpin BJ, Loechel F, Mattei MG, Engvall E, Albrechtsen R, Wewer UM. A novel, secreted form of human ADAM 12 (meltrin alpha) provokes myogenesis in vivo. J Biol Chem 1998;273:157-166.

14. Brzoska E, Bello V, Darribere T, Moraczewski J. Integrin alpha3 subunit participates in myoblast adhesion and fusion in vitro. Differentiation 2006;74:105-118.

15. Thodeti CK, Albrechtsen R, Grauslund M, Asmar M, Larsson C, Takada Y, Mercurio AM, Couchman JR, Wewer UM. ADAM12/ syndecan-4 signaling promotes beta 1 integrin-dependent cell spreading through protein kinase calpha and rhoa. J Biol Chem 2003;278: 9576-9584.

16. Thodeti CK, Frohlich C, Nielsen CK, Takada Y, Fassler R, Albrechtsen $\mathrm{R}$, Wewer UM. ADAM12-mediated focal adhesion formation is differently regulated by beta1 and beta3 integrins. FEBS Lett 2005; 579:5589-5595.

17. Asakura M, Kitakaze M, Takashima S, Liao Y, Ishikura F, Yoshinaka $\mathrm{T}$, Ohmoto $\mathrm{H}$, Node $\mathrm{K}$, Yoshino $\mathrm{K}$, Ishiguro $\mathrm{H}$, et al. Cardiac hypertrophy is inhibited by antagonism of ADAM12 processing of HB-EGF: Metalloproteinase inhibitors as a new therapy. Nat Med 2002;8:35-40

18. Rocks N, Estrella C, Paulissen G, Quesada-Calvo F, Gilles C, Gueders M, Crahay C, Foidart Jean-M, Gosset P, Noël A, et al. The metalloproteinase ADAM-12 regulates bronchial epithelial cell proliferation and apoptosis. Cell Prolif 2008;41:988-1001.

19. White JM. ADAMs: modulators of cell-cell and cell-matrix interactions. Curr Opin Cell Biol 2003;15:598-606.
20. Peduto L, Reuter VE, Sehara-Fujisawa A, Shaffer DR, Scher HI, Blobel CP. ADAM12 is highly expressed in carcinoma-associated stroma and is required for mouse prostate tumor progression. Oncogene 2006;25: 5462-5466.

21. Le Pabic H, Bonnier D, Wewer UM, Coutand A, Musso O, Baffet G, Clement B, Theret N. ADAM12 in human liver cancers: TGF-betaregulated expression in stellate cells is associated with matrix remodeling. Hepatology 2003;37:1056-1066.

22. Kodama T, Ikeda E, Okada A, Ohtsuka T, Shimoda M, Shiomi T, Yoshida K, Nakada M, Ohuchi E, Okada Y. ADAM12 is selectively overexpressed in human glioblastomas and is associated with glioblastoma cell proliferation and shedding of heparin-binding epidermal growth factor. Am J Pathol 2004;165:1743-1753.

23. Bradding P, Mediwake R, Feather IH, Madden J, Church MK, Holgate ST, Howarth PH. TNF alpha is localized to nasal mucosal mast cells and is released in acute allergic rhinitis. Clin Exp Allergy 1995;25:406415.

24. Bachert C, Wagenmann M, Hauser U. Proinflammatory cytokines: Measurement in nasal secretion and induction of adhesion receptor expression. Int Arch Allergy Immunol 1995;107:106-108.

25. Demoly P, Crampette L, Lebel B, Campbell AM, Mondain M, Bousquet J. Expression of cyclo-oxygenase 1 and 2 proteins in upper respiratory mucosa. Clin Exp Allergy 1998;28:278-283.

26. Just N, Tillie-Leblond I, Guery BP, Fourneau C, Tonnel AB, Gosset P. Keratinocyte growth factor (KGF) decreases ICAM-1 and VCAM-1 cell expression on bronchial epithelial cells. Clin Exp Immunol 2003; 132:61-69.

27. Mukaida N. Pathophysiological roles of interleukin-8/CXCL8 in pulmonary diseases. Am J Physiol 2003;284:L566-L577.

28. Subramanian S, Boder ET, Discher DE. Phylogenetic divergence of CD47 interactions with human signal regulatory protein alpha reveals locus of species specificity: implications for the binding site. J Biol Chem 2007;282:1805-1818.

29. Zen K, Parkos CA. Leukocyte-epithelial interactions. Curr Opin Cell Biol 2003;15:557-564.

30. Mette SAPJ, Buck CA, Albelda SM. Distribution of integrin cell adhesion receptors on normal bronchial epithelial cells and lung cancer cells in vitro and in vivo. Am J Respir Cell Mol Biol 1993;8: 562-572.

31. Huang J, Bridges LC, White JM. Selective modulation of integrinmediated cell migration by distinct adam family members. Mol Biol Cell 2005;16:4982-4991.

32. Kuhn C III, Boldt J, King TE Jr, Crouch E, Vartio T, McDonald JA. An immunohistochemical study of architectural remodeling and connective tissue synthesis in pulmonary fibrosis. Am Rev Respir Dis 1989; 140:1693-1703

33. White SR, Dorscheid DR, Rabe KF, Wojcik KR, Hamann KJ. Role of very late adhesion integrins in mediating repair of human airway epithelial cell monolayers after mechanical injury. Am J Respir Cell Mol Biol 1999;20:787-796.

34. Puchelle E, Zahm JM, Tournier JM, Coraux C. Airway epithelial repair, regeneration, and remodeling after injury in chronic obstructive pulmonary disease. Proc Am Thorac Soc 2006;3:726-733.

35. Liu Y, Shaw SK, Ma S, Yang L, Luscinskas FW, Parkos CA. Regulation of leukocyte transmigration: Cell surface interactions and signaling events. J Immunol 2004;172:7-13.

36. Parkos CA, Colgan SP, Diamond MS, Nusrat A, Liang TW, Springer TA, Madara JL. Expression and polarization of intercellular adhesion molecule-1 on human intestinal epithelia: consequences for cd11b/ cd18-mediated interactions with neutrophils. Mol Med 1996;2:489505.

37. Taguchi M, Sampath D, Koga T, Castro M, Look DC, Nakajima S, Holtzman MJ. Patterns for rantes secretion and intercellular adhesion molecule 1 expression mediate transepithelial $\mathrm{T}$ cell traffic based on analyses in vitro and in vivo. J Exp Med 1998;187:1927-1940.

38. Shinohara M, Ohyama N, Murata Y, Okazawa H, Ohnishi H, Ishikawa O, Matozaki T. CD47 regulation of epithelial cell spreading and migration, and its signal transduction. Cancer Sci 2006;97:889-895.

39. Liu Y, Merlin D, Burst SL, Pochet M, Madara JL, Parkos CA. The role of CD47 in neutrophil transmigration. Increased rate of migration correlates with increased cell surface expression of CD47. J Biol Chem 2001;276:40156-40166.

40. Parkos CA, Colgan SP, Liang TW, Nusrat A, Bacarra AE, Carnes DK, Madara JL. Cd47 mediates post-adhesive events required for neutrophil migration across polarized intestinal epithelia. J Cell Biol 1996; 132:437-450. 
41. Ohnishi H, Kobayashi H, Okazawa H, Ohe Y, Tomizawa K, Sato R, Matozaki T. Ectodomain shedding of SHPS-1 and its role in regulation of cell migration. J Biol Chem 2004;279:27878-27887.

42. Lemjabbar H, Basbaum C. Platelet-activating factor receptor and ADAM10 mediate responses to staphylococcus aureus in epithelial cells. Nat Med 2002;8:41-46.

43. Shao MX, Ueki IF, Nadel JA. Tumor necrosis factor alpha-converting enzyme mediates muc5ac mucin expression in cultured human airway epithelial cells. Proc Natl Acad Sci USA 2003;100:1161811623.

44. Nadel JA. Role of epidermal growth factor receptor activation in regulating mucin synthesis. Respir Res 2001;2:85-89.

45. Le Quement C, Guenon I, Gillon JY, Lagente V, Boichot E. Mmp-12 induces IL-8/CXCL8 secretion through EGFR and ERK1/2 activation in epithelial cells. Am J Physiol 2008;294: L1076-L1084. 